\title{
APÉNDICES INTERROGATIVOS EN EL HABLA DE SEVILLA: UN ESTUDIO EN TIEMPO REAL
}

Fecha de recepción: 03.10.2018

Fecha de aceptación: 26.11 .2018

Resumen: En esta investigación abordamos el estudio de los apéndices interrogativos en la ciudad de Sevilla teniendo en cuenta el contraste entre dos épocas: últimas décadas del siglo XX (materiales del grupo Sociolingüística Andaluza: Estudio Sociolingüístico del Habla de Sevilla) y primeros años del siglo XXI (corpus PRESEEA-SE recopilado por el proyecto Patrones Sociolingüísticos del Español de Sevilla). El objetivo que se persigue es conocer si el factor cronológico ha influido en el tipo y la vitalidad de los apéndices interrogativos registrados, así como en su distribución sociolingüística. Para ello se consideraron las variables nivel educativo, edad y sexo. Nuestros resultados ponen de manifiesto que hay formas que muestran un comportamiento similar en ambas etapas, aunque con algunas diferencias generacionales ( $i n o ?, ~ ¿ e h$ ?); y que hay otras variantes cuya distribución está condicionada por la fecha de recogida de los materiales y, especialmente, por la edad de los informantes (¿entiendes?, ¿verdad?, ¿vale?, ¿sabes?).

Palabras clave: marcadores del discurso, apéndices interrogativos, Sevilla, sociolingüística, estudio en tiempo real

Title: Tag Questions in Sevillian Speech: A Real Time Study

\begin{abstract}
In this investigation we studied the tag questions in Seville considering the contrast between these two periods of time: the last decades of the 20th century (samples from the Sociolingüística Andaluza group: Estudio Sociolingüístico del Habla de Sevilla) and the beginning of the 21st century (PRESEEA-SE corpus compiled by the Patrones Sociolingüisticos del Español de Sevilla project). The basic purpose is to know if the chronological factor has any influence over the registered tag questions and their vivid usage, as well over their sociolinguistic distribution. For it, we considered the following variables: educational level, age and gender. The results showed a similar behaviour between elements from the two periods of time, although with some differences in the age groups ( $i n o$ ?, ¿eh?). We also noticed that there are other variants whose distribution is conditioned by the date of sample collection and, particularly, by the informants' age (¿entiendes?, ¿verdad?, ¿vale?, ¿sabes?).
\end{abstract}

Key words: discourse markers, tag questions, Seville, Sociolinguistics, real time study

$1 \quad$ Esta investigación se inserta dentro del proyecto Patrones Sociolingüisticos del Español de Sevilla (PASOS-SE) [Proyecto de Excelencia I+D+I, convocatoria de 2015, referencia FFI2015-68171-C5-3-P, financiado por el Ministerio de Economía y Competitividad de España y por el Fondo Europeo de Desarrollo Regional]. 


\section{PRESENTACIÓN}

Los estudios sobre marcadores del discurso en la ciudad de Sevilla cuentan ya con una amplia tradición. Los resultados iniciales se obtuvieron en la década de los noventa, a partir de las investigaciones de Fuentes (1990a, 1990b, 1990c, 1993a, 1993b). En aquella ocasión se partía de los materiales del habla hispalense recopilados entre 1972 y finales de la década de los ochenta ${ }^{2}$ por el grupo de investigación Sociolingüistica Andaluza: Estudio Sociolingüístico del Habla de Sevilla (HUM-141), los cuales habían sido distribuidos entre los niveles socioculturales culto (Lamíquiz y Pineda 1983), medio (Pineda y Ollero 1992) y popular (Lamíquiz y Ropero 1987). Posteriormente se han llevado a cabo análisis en los que se han estudiado estas unidades lingüísticas en nuevos materiales, integrados actualmente en el corpus PRESEEA-SE, recogidos entre los años 2009 y 2018 por los integrantes del proyecto Patrones Sociolingüísticos del Español de Sevilla (PASOS-SE). En esta etapa hay que diferenciar entre las investigaciones centradas en el estudio de los marcadores discursivos en las muestras de habla recientes (Santana 2019) y las que plantean un estudio contrastivo entre las dos épocas señaladas (Santana 2014, 2015a, 2015b, 2016, 2017). El trabajo que se presenta aquí se sitúa en esta segunda línea: análisis en tiempo real del comportamiento de un grupo específico de marcadores discursivos, los apéndices interrogativos, teniendo en cuenta los sociolectos alto y bajo de las dos submuestras ya mencionadas ${ }^{3}$. La finalidad última es conocer si se producen semejanzas y, sobre todo, diferencias significativas en el tipo de unidades empleadas y en su distribución sociolingüística entre una y otra época. Teniendo en cuenta los datos obtenidos en Santana (2019), partimos de la hipótesis de que se están produciendo ciertos movimientos generacionales en las unidades que se utilizan, bien porque los jóvenes han incorporado a su discurso nuevas formas, bien porque se aprecia la pervivencia de ciertos elementos en los informantes de mayor edad. La perspectiva longitudinal de este trabajo busca corroborar esas premisas iniciales: que hay ciertos usos característicos de los sujetos de menor edad de las encuestas recientes que no se daban en los años setenta y ochenta y que los apéndices interrogativos que en la actualidad solo se mantienen en los sujetos del tercer grupo etario estaban más extendidos en las encuestas previas. Por tanto, las variables época y edad serán de especial relevancia.

\footnotetext{
2 No hay documentación precisa sobre la fecha concreta en la que se hicieron las grabaciones del sociolecto medio. No obstante, si tenemos en cuenta que las del nivel popular se hicieron entre los años 1984 y 1986 (Lamíquiz y Ropero 1987: 16) y que las del nivel medio, que se realizaron con posterioridad, se publicaron en el año 1992, es lógico que estas muestras de habla se recopilaran en los últimos años de la década de los ochenta.

3 Los materiales del nivel educativo intermedio no han podido utilizarse para esta investigación porque cuando se estaba llevando a cabo esas muestras estaban todavía en fase de recopilación.
} 


\section{MARCO TEÓRICO}

Los apéndices interrogativos son partículas que el hablante utiliza en el intercambio dialógico para reclamar la atención del interlocutor, con quien busca mantener el contacto, y para cerciorarse de que el proceso comunicativo fluye sin problemas de seguimiento o de comprensión. El carácter fático es, por tanto, una de las principales características de estas partículas (Cestero 2019: 19). Briz las denomina marcadores de control de contacto, en tanto que "implican activamente al interlocutor" en el proceso comunicativo y lo hacen partícipe de "razonamientos de los hablantes" (2001: 224-225). San Martín se suma a esta denominación y considera que son unidades "mediante las cuales los hablantes mantienen la atención y controlan la comprensión del resto de los participantes en un intercambio comunicativo" (2011: 139). Por su parte, Cestero resalta también su carácter fático, en tanto que son elementos que sirven para "asegurarse de que el canal de comunicación está abierto y funciona, es decir, confirmar que se mantiene la atención y el seguimiento continuos" (2002: 620). El intercambio entre el yo y el tú delata también una faceta exhortativa. Este es el aspecto que autores como Fuentes (1990a), Galué (2002: 36) Cortés y Camacho (2005: 165-177) y Fuentes y Brenes (2014: 186) han considerado como una de las principales características que definen su funcionamiento. A este respecto, para Fuentes los apéndices con valor apelativo "tienen como función apelar al oyente, llamar su atención, pedir su colaboración en el acto discursivo" (1990a: 172).

A estas funciones básicas fática y apelativa se les suman otras más específicas que, sin pretensión de exhaustividad, sintetizamos en una clasificación inicial que sigue de cerca la propuesta de Cestero (2003: 87-96) y Cestero (2019: 22-26).

Búsqueda de ratificación. Este es uno de los rasgos más característicos de estas partículas. Así se aprecia ya en el trabajo pionero de Ortega (1985) o en el de Martín Zorraquino y Portolés Lázaro (1999: 4188), cuando denominan a estos elementos comprobativos. En unos casos la constatación va dirigida hacia el contenido al que acompaña el marcador (1). Es lo que Cestero llama "búsqueda de ratificación de acierto" (2003: 89). El hablante requiere la complicidad del oyente para constatar que comparte con él la información que está aportando. Se trata de lo que Móccero delimita como "petición de confirmación de hechos" (2010: 71). García Vizcaíno, en su análisis de ¿no?, señala que este proceso de constatación admite la paráfrasis por “¿no es así?” (2005: 91-92). En ocasiones, incluso, el interlocutor reacciona verbalmente a este requerimiento y da una respuesta.

(1) Bueno, lo primero que tengo entre ojos es la tesis doctoral, como tú bien sabes, ¿no?, pero que no sé cuándo la acabaré, pues cada vez la veo más larga y más liada. Así que no sé. (XX-M13-081)

En otros casos la búsqueda de consenso va dirigida hacia el acuerdo sobre una opinión expresada (2). El hablante trata de cerciorarse de que su interlocutor es de su mismo parecer. Es lo que Cestero identifica como "búsqueda de ratificación de acuerdo" (2003: 88) 
y Móccero como "petición de evaluación” (2010: 71). Para estos casos, García Vizcaíno propone la paráfrasis por “¿no crees?” o “¿no estás de acuerdo?” (2005: 91-92).

(2) con ese el < vacilación/> ese ruedo / con ese albero tan bonito que le da tanto colorido ¿verdad? a la plaza. (XXI-M33-069)

Comprobación de la continuidad de la interacción. Aquí el apéndice interrogativo se utiliza como estrategia que mantiene abierta la comunicación con el oyente, al que alude en su discurso. Fuentes y Brenes señalan que hay contextos en los que estas unidades se especializan en "la simple constatación del desarrollo del proceso de comunicación, llegando a convertirse en elementos fáticos" (2014: 186). García Vizcaíno mantiene para estos casos la posible paráfrasis por “ime sigues?” (2005: 92). Este valor se da especialmente cuando el marcador se convierte en una fórmula recurrente en la intervención de un sujeto y constituye un apoyo discursivo que favorece el avance de la información, como se aprecia en (3).

(3) ¿lo que más me gusta de mi casa? / $\mathrm{mmm}<$ silencio/> no sé / me gusta entera la casa / ¿no? pero eh lo que más me gusta de la casa es que no tengo vecinos arriba ni abajo $<$ risas $=$ „E"/> / que es una casa ¿no? he vivido siempre en casa ¿no? y la verdad que cuando me metí en un piso / pues bueno / era lo que había ¿no? no se podía otra cosa // y luego con el tiempo pues al final / vinimos a una casa ¿no? (XXI-H23-055)

Constatación de entendimiento o de conocimiento. El hablante reclama la atención del interlocutor para que le corrobore que entiende o que conoce una información. A este respecto, Ortega hablaba de tratar de "deshacer la ignorancia" del oyente (1986: 275). Aquí prevalecen aquellas partículas que proceden de formas verbales del campo semántico de la 'percepción intelectual' como ¿entiendes?, ¿comprendes? (4) o ¿sabes?

(4) Pero ya se van convenciendo que la huelga no le trae nada bueno, ¿comprendes?, no le trae nada más que perjuicios para ellos mismos, porque ellos saben que, ahora, este mes, van a llevar doce mil pesetas menos en el salario. (XX-H31-012)

Enfatización. En ocasiones se busca al oyente para focalizar su atención en un contenido, que queda informativamente destacado, con la finalidad de que no le pase desapercibido. Esto es lo que García Vizcaíno (2005: 94) y Rodríguez Muñoz (2009: 94) llaman "refuerzo expresivo", función que ambos autores comprueban que es muy rentable en el caso de ¿eh? (5).

(5) y me dice / quillo Paco este número me suena a mí ¿eh? (XXI-H31-011)

Los valores señalados pueden superponerse y combinarse en una misma partícula y en un mismo contexto. En todos los apéndices interrogativos permanece el carácter fático y apelativo que los caracteriza, a lo que puede sumarse uno o varios de los matices que se han desglosado arriba (Cestero 2002: 622, Fuentes y Brenes 2014: 191, Cestero 2019: 8). Se trata, pues, de recursos plurifuncionales que adoptan más de un papel 
en el entorno comunicativo, característica que es habitual en los marcadores del discurso. Esta cualidad puede verse como una dificultad a la hora de analizar estos elementos desde el punto de vista cuantitativo y variacionista (Cortés 1998: 151), pero no como un obstáculo insalvable. Como indica este autor, "las variables del discurso se pueden determinar a partir de una función común en el discurso", lo que permitiría avalar "la equivalencia semántica de las variantes" (154). De forma similar a como se ha hecho en San Martín (2011) o en Lewis Vergara (2016), en este trabajo tomamos como variable el valor fundamental o básico que agrupa a todas estas unidades, su carácter fático y apelativo. En efecto, como hemos señalado, todos estos marcadores interrogativos buscan establecer el contacto con el interlocutor y reclamar de él su cooperación para asegurarse del éxito del intercambio comunicativo, al margen de que en cada entorno discursivo se puedan actualizar una o varias de las funciones pragmáticas señaladas.

\section{LA MUESTRA}

El corpus empleado para esta investigación está compuesto por un total de 96 grabaciones recopiladas, siguiendo la técnica de encuesta semidirigida y distribuidas según la variable época, con 48 grabaciones por estadio cronológico. A su vez, en cada uno de ellos se consideraron las variables sociales: nivel educativo ( 24 del sociolecto alto, con formación universitaria, y 24 del sociolecto bajo, con formación primaria o sin estudios), edad (encuestas antiguas: $1^{\text {a }}$ generación hasta 32 años; $2^{\text {a }}$ generación entre 33 y 49 años; $3^{\text {a }}$ generación de 50 años en adelante; encuestas recientes: $1^{a}$ generación hasta 34 años;

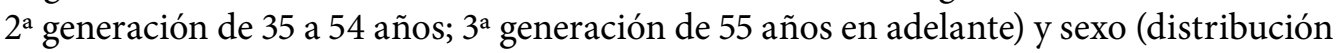
equilibrada entre hombres y mujeres). Para establecer los cortes etarios que hemos indicado arriba hubo que tomar una serie de decisiones encaminadas a tener muestras equiparables que pudieran ser objeto de un estudio contrastivo. De este modo, como los criterios para dividir los grupos de edad de los sujetos encuestados en cada época no eran los mismos, tuvimos que hacer una redistribución del material que asegurara la fiabilidad de los resultados. Concretamente, acomodamos los cortes generacionales con los que se trabajó en las submuestras antiguas ( $1^{\text {a }}$ generación menor de 30 años, $2^{\text {a }}$ generación de 30 a 45 años y $3^{\text {a }}$ generación de 46 en adelante) a los de las entrevistas más recientes, que están respaldadas por la metodología de PRESEEA. Como resultado de este reajuste, los informantes del siglo XX se reagruparon en bloques ligeramente heterogéneos: sociolecto alto ( $1^{\mathrm{a}}$ generación: 8 sujetos, $2^{\mathrm{a}}$ generación: $9,3^{\mathrm{a}}$ generación: 7$)$ y sociolecto bajo ( $1^{\text {a }}$ generación: 11 sujetos, $2^{\text {a }}$ generación: $6,3^{\text {a }}$ generación: 7 ), mientras que los sujetos del siglo XXI se repartían de forma homogénea en bloques de 8 informantes por sector de edad. Esto fue común a ambos niveles educativos.

Aunque las muestras de las dos etapas eran bastante parecidas en lo que respecta a la técnica utilizada para obtener las grabaciones y a la temática que se abordaba en ellas (el investigador va encauzando la conversación con el encuestado hacia aspectos cotidianos como la rutina diaria, el barrio en el que vive, las relaciones familiares o las tradiciones de la ciudad hispalense, entre otros), también hay que señalar 
las diferencias que presentaban en lo que respecta a su duración. En efecto, las primeras grabaciones del nivel culto que se realizaron en los años setenta contenían menos minutos (entre 20 y 30) que las demás (generalmente entre 30 y 40-45) y, en consecuencia, el número de palabras que incluían era también menor. Teniendo en cuenta esta circunstancia, era preciso adaptar los materiales iniciales a los objetivos de nuestra investigación que, al ser de carácter contrastivo, requería que las muestras comparadas tuvieran características idénticas o lo más similares posible. Solo así estaríamos en disposición de garantizar la rigurosidad de los resultados obtenidos. Para cumplir este requisito, optamos por analizar un número de palabras similar o igual en todos los informantes. Este parámetro nos parecía más fiable que el de seleccionar la misma cantidad de minutos de cada entrevista, pues en este caso nos arriesgábamos a que la mayor o menor rapidez en la dicción de los sujetos tuviera como resultado muestras más dispares. Para determinar cuál sería el número de palabras que tomábamos como base para nuestro análisis tuvimos que adoptar como punto de referencia las encuestas antiguas del sociolecto alto que, como hemos dicho, eran más cortas. Más concretamente, tomamos la media de palabras transcritas en estas grabaciones, 2500, como la dimensión que deberían tener todas las encuestas consideradas para nuestro estudio. Hay que aclarar que para el recuento de vocablos solo tuvimos en cuenta los parlamentos producidos por los informantes.

En lo que respecta a los fragmentos que hemos seleccionado como ejemplos, la transcripción de los que fueron tomados de las primeras grabaciones no tienen etiquetado, mientras que los procedentes de las entrevistas más recientes llevan las etiquetas propuestas por PRESEEA. Para identificar a los sujetos, en primer lugar se señala la época mediante XX o XXI, según corresponda. Seguidamente se diferencia entre hombre $(H)$ y mujer $(M)$, la generación $(1,2,3)$ y el nivel educativo (bajo: 1 y alto: 3). A continuación se indica la numeración asignada a cada informante: sociolecto bajo entre 1 y 24 , sociolecto alto entre 49 y 72.

\section{ANÁLISIS Y RESULTADOS}

Los materiales del habla de Sevilla analizados arrojaron un total de 1493 apéndices interrogativos, los cuales se distribuyeron en 12 formas distintas, según se puede apreciar en el Gráfico 1.

Si hacemos la distinción por épocas, se percibe un reparto bastante similar en las dos etapas cronológicas exploradas, aunque con un incremento de su uso en la submuestra del siglo XX (863/1493, 57,8 \%), como se ve en el Gráfico 2. En cualquier caso, se comprueba que son recursos que están ampliamente presentes en el discurso de los informantes sevillanos en una y en otra etapa.

$\mathrm{Al}$ poner en relación los registros de cada estadio cronológico con las variables sociales consideradas hemos observado una diferencia llamativa en lo que respecta al nivel educativo. En el Gráfico 3 se percibe que, al comparar las dos submuestras, las tendencias se invierten. Si bien a finales del siglo XX estas partículas eran más recurrentes entre los sujetos con escasa formación, en la actualidad los índices son superiores entre los informantes con formación universitaria. 


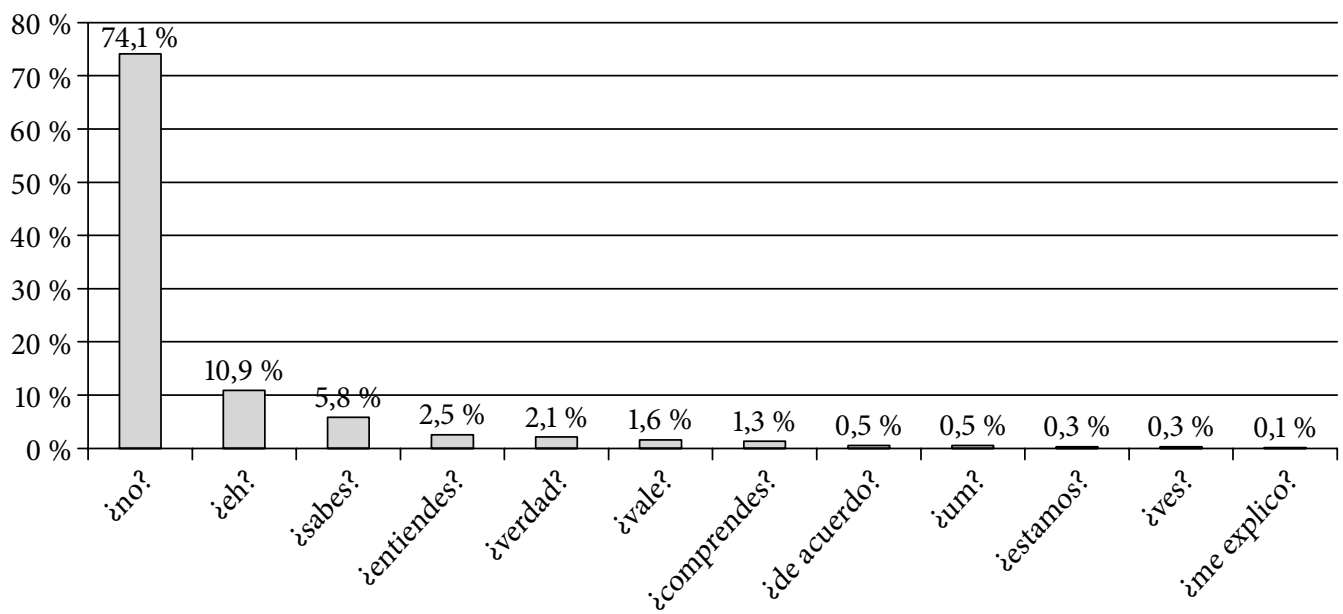

Gráfico 1 Distribución global según apéndice interrogativo.

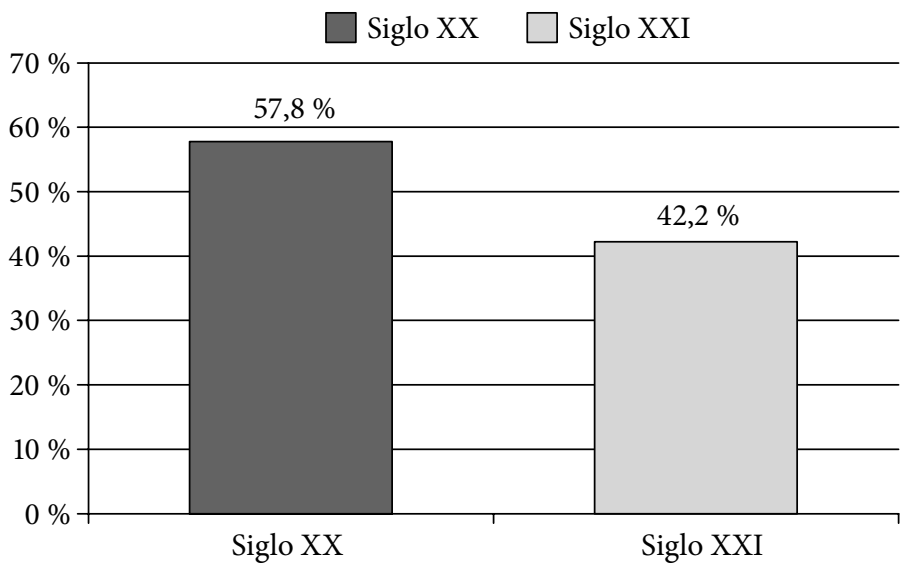

Gráfico 2 Distribución global según época.

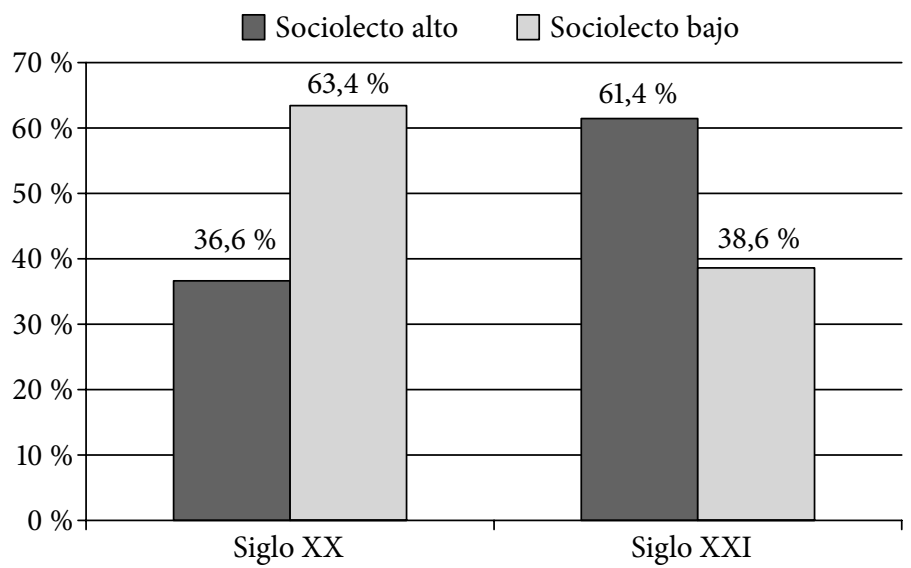

Gráfico 3 Distribución global según época y nivel educativo. 
Ahora bien, si nos fijamos en la edad de los informantes, tanto en el sociolecto alto (Gráfico 4) como en el bajo (Gráfico 5), los encuestados de la segunda y la tercera generación muestran una línea ascendente en el empleo de estos marcadores, mientras que los jóvenes reflejan un acusado descenso en su uso en las encuestas recientes. Quizá esté latente la idea entre los sujetos de menos edad, sobre todo en aquellos con más formación académica y, por tanto, con mayor grado de autocrítica acerca de sus usos lingüísticos, de que el empleo recurrente de estas estrategias en sus intervenciones se identifica con un discurso mal construido, que tiende a ser juzgado negativamente.

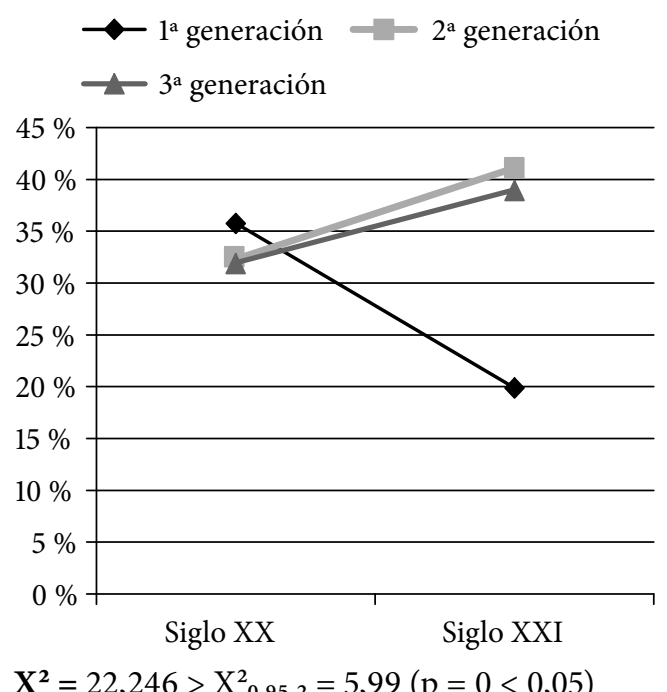

Gráfico 4 Sociolecto alto: distribución según época y edad.

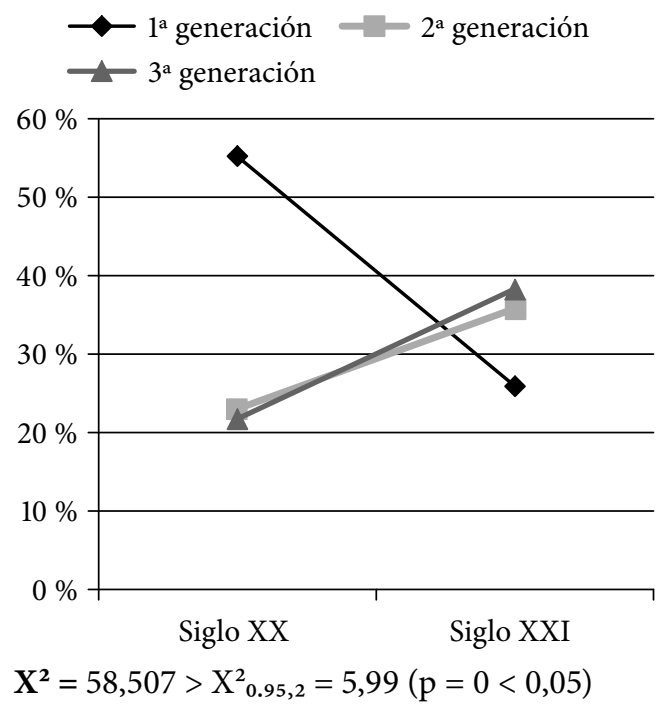

Gráfico 5 Sociolecto bajo: distribución según época y edad.

Cuadro 1 Distribución de apéndices interrogativos según época

\begin{tabular}{l|c|c|c|c|} 
& \multicolumn{2}{|c|}{ Siglo XX } & \multicolumn{2}{c}{ Siglo XXI } \\
\hline ¿no? & n & \% & n & \% \\
¿eh? & 716 & $83,0 \%$ & 390 & $61,9 \%$ \\
¿sabes? & 63 & $7,3 \%$ & 100 & $15,9 \%$ \\
¿entiendes? & 17 & $2,0 \%$ & 70 & $11,1 \%$ \\
¿verdad? & 21 & $2,4 \%$ & 17 & $2,7 \%$ \\
¿vale? & 25 & $2,9 \%$ & 6 & $1,0 \%$ \\
¿comprendes? & 0 & $0,0 \%$ & 24 & $3,8 \%$ \\
¿de acuerdo? & 15 & $1,7 \%$ & 4 & $0,6 \%$ \\
¿um? & 0 & $0,0 \%$ & 8 & $1,3 \%$ \\
¿estamos? & 0 & $0,0 \%$ & 7 & $1,1 \%$ \\
¿ves? & 4 & $0,5 \%$ & 0 & $0,0 \%$ \\
¿me explico? & 1 & $0,1 \%$ & 3 & $0,5 \%$ \\
SUBTOTALES & 1 & $0,1 \%$ & 1 & $0,2 \%$ \\
\hline
\end{tabular}


Los índices de frecuencia globales ya señalados quedan repartidos por apéndice interrogativo y etapa cronológica, como aparece en el Cuadro 1.

En términos generales no se perciben grandes diferencias en cuanto al tipo de partículas. No obstante, aunque la mayoría de ellas son compartidas por ambas épocas (8/12, $66,7 \%)$, las encuestas recientes arrojaron una mayor diversidad de formas: siglo XX 9/12 (75,0 \%) y siglo XXI 11/12 (91,7 \%). Seguidamente haremos un estudio individualizado más detenido de aquellos interrogativos que aportaron datos relevantes para la investigación.

\section{¿No?}

Este fue el apéndice más característico del habla de Sevilla en las dos épocas analizadas y, a juzgar por los datos que tenemos de la norma culta hispánica (Santana 2017: 243), es también el más empleado en la mayoría de las ciudades hispanohablantes. Este carácter prototípico no solo se debe a los porcentajes de uso documentados, sino también a que registró una distribución bastante homogénea en toda la muestra, en tanto que fue utilizado por la mayor parte de los informantes: 84/96 (87,5\%) en los dos estadios cronológi$\cos (40 / 48,83,3 \%$ en las encuestas antiguas y $44 / 48,91,7 \%$ en las recientes); y en la mayoría de ellos fue el elemento más destacado, a veces el único que se empleó: 76,2 \% (64/84) en las dos épocas (34/40, 85,0 \% en las encuestas iniciales y 30/44, 68,2 \% en las actuales).

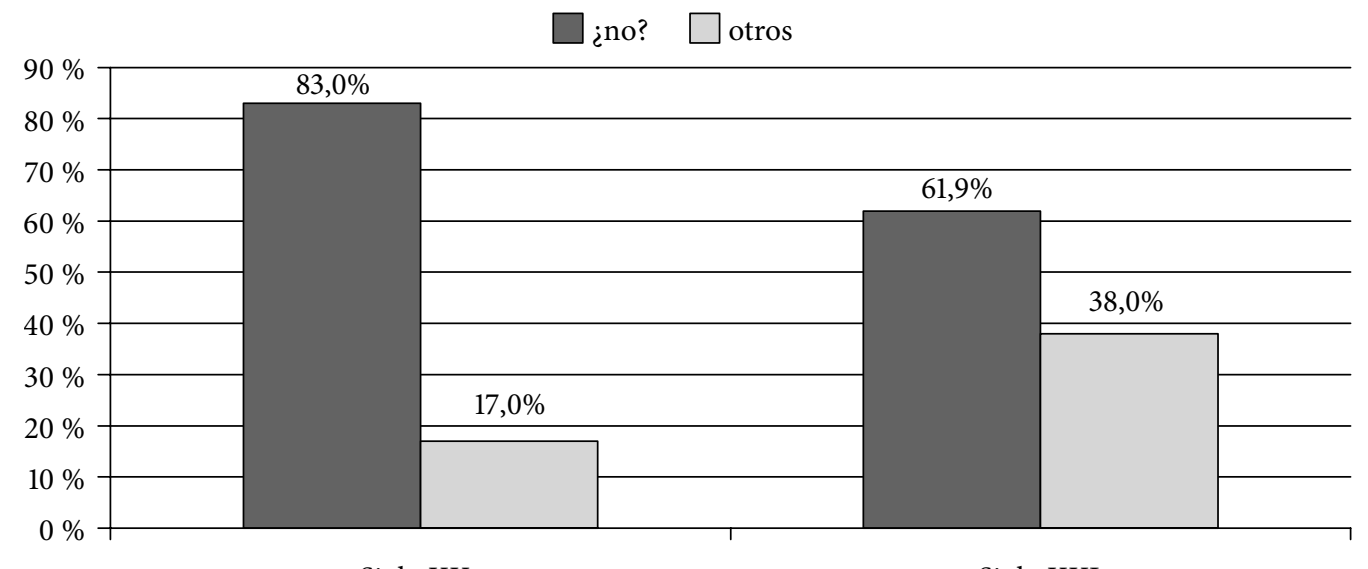

Siglo XX

Siglo XXI

$\mathrm{X}^{2}=385,926>\mathrm{X}^{2} .95,1=3,84(\mathrm{p}=0<0,05)$

Gráfico 6 Representatividad de ¿no? según época.

En los materiales de finales del siglo XX este marcador obtuvo índices de frecuencia más significativos con respecto al resto de formas empleadas (716/863, 83,0 \%). Nos decantamos por pensar que esto tenga que ver con que en las grabaciones antiguas se registró un menor número de partículas distintas, por lo que las funciones características de estas unidades estarían concentradas en menos elementos, entre los que sobresale ¿no? 
Si ponemos en relación los usos de este apéndice interrogativo con el nivel educativo (Gráfico 7) vemos que, al igual que sucedía con los índices generales, con el paso del tiempo ha aumentado el registro en el sociolecto alto y ha descendido en el bajo. La preferencia de este marcador en sujetos con formación universitaria coincide con los resultados de Cestero (2019: 48) para el habla de Madrid. A este respecto, habría que seguir indagando sobre si este es un patrón que se repite en otras áreas de habla hispana.

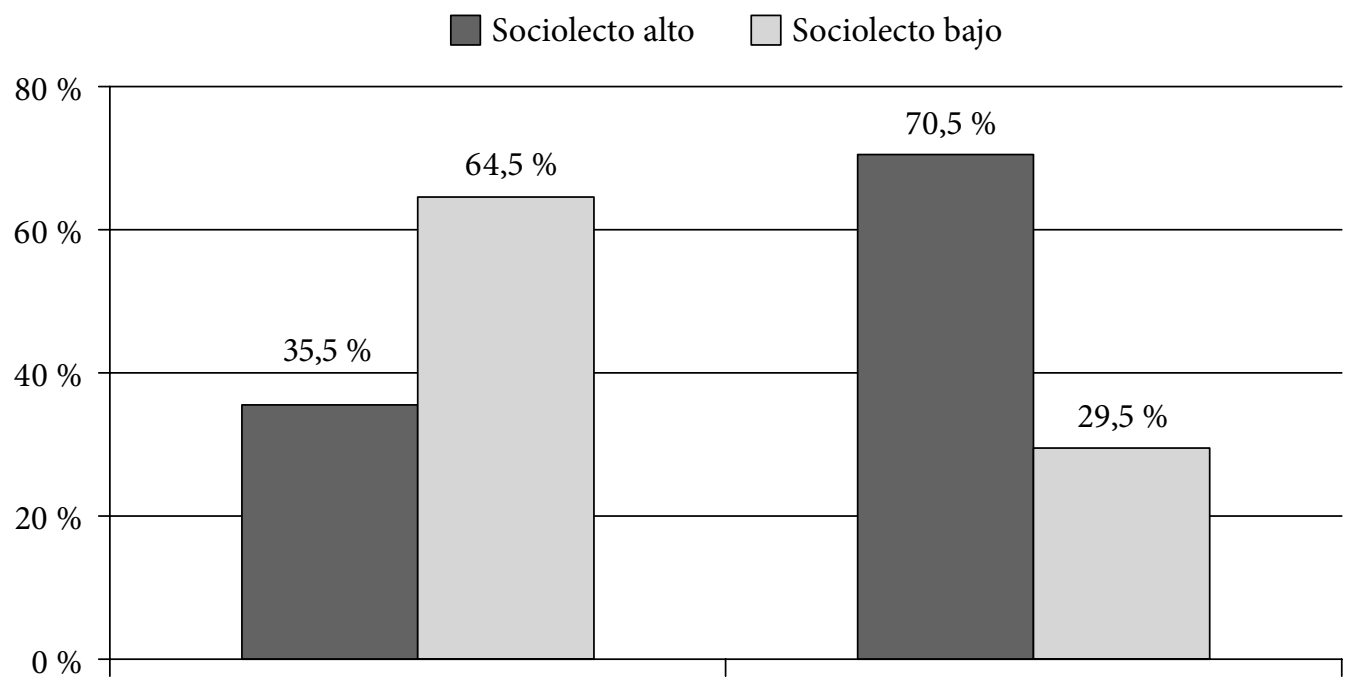

Siglo XX

Siglo XXI

$\mathrm{X}^{2}=124,216>\mathrm{X}_{0.95,1}^{2}=3,84(\mathrm{p}=0<0,05)$

Gráfico 7 Distribución de ¿no? según época y sociolecto.

No obstante, combinando edad y nivel educativo (Gráficos 8 y 9) se comprueba que, aunque hay más casos de ¿no? en los sujetos con formación universitaria en las grabaciones recientes, los jóvenes son los que menos lo emplean y muestran un acusado descenso con respecto a la etapa precedente. Esto sucede también en los informantes de instrucción baja. Se trata, por tanto, de un apéndice interrogativo que tiende a emplearse cada vez menos entre el primer grupo etario. Si tenemos en cuenta que los jóvenes de los años setenta son los mayores de la época actual, cabe señalar que se ha mantenido e incluso ha aumentado la tendencia a incluir esta estrategia en su discurso.

Cestero y Albelda (2012: 96) demostraron que este marcador, como estrategia de atenuación, fue más empleado por los varones en las muestras de habla de Madrid y de Valencia. Más recientemente, Cestero comprueba que ¿no? es un recurso más recurrente en los hombres madrileños, especialmente con la función de "comprobar acuerdo o acierto" (2019: 45). Para la ciudad de Sevilla (Gráfico 10) se comprueba que esta es una característica que se mantiene en ambas épocas. Los hombres, por tanto, en lo que respecta al uso de este marcador, tienden a ser más conciliadores, buscando de forma más recurrente la complicidad del interlocutor. 
$\sim 1^{\mathrm{a}}$ generación

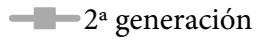

$-3^{a}$ generación

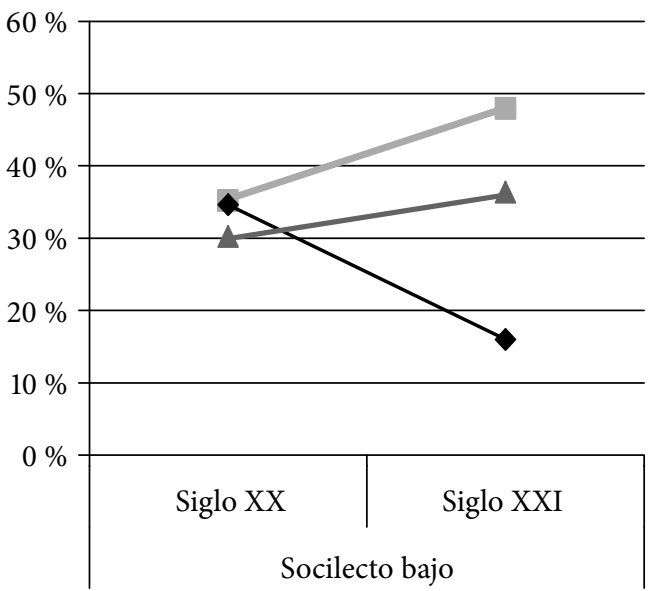

$\mathbf{X}^{2}=24,841>\mathrm{X}_{0.95,2}^{2}=5,99(\mathrm{p}=0<0,05)$

Gráfico 8 Sociolecto alto: distribución de ¿no? según época y edad.

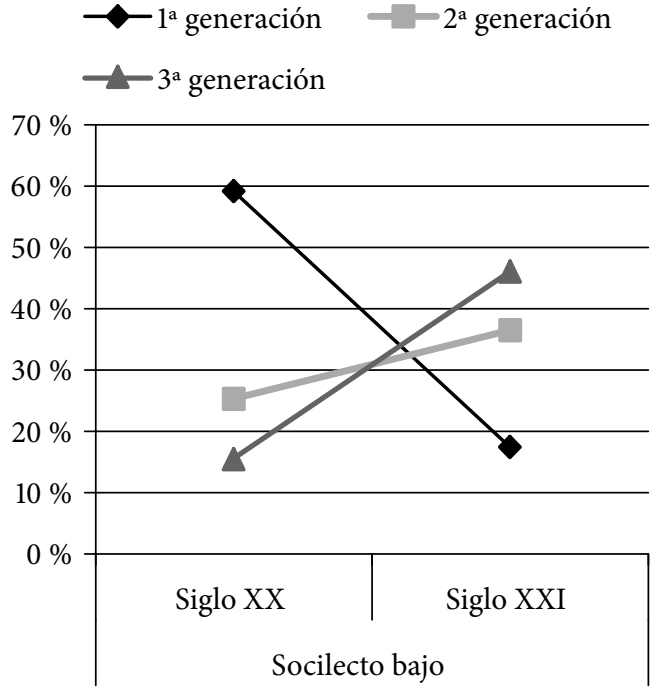

$\mathrm{X}^{2}=75,266>\mathrm{X}^{2}{ }_{0.95,2}=5,99(\mathrm{p}=0<0,05)$

Gráfico 9 Sociolecto bajo: distribución de ¿no? según época y edad.

\section{Hombre $\square$ Mujer}

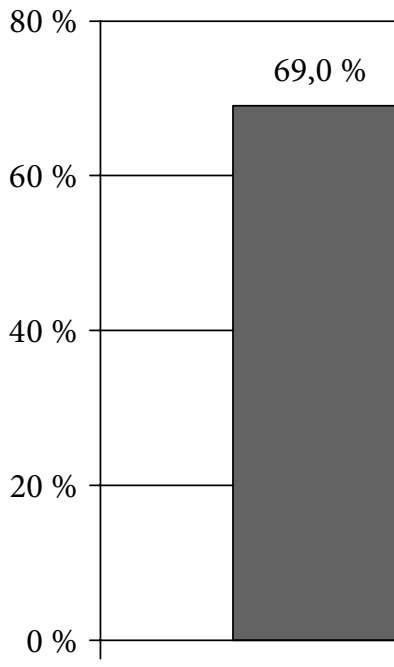

Siglo XX
$64,6 \%$

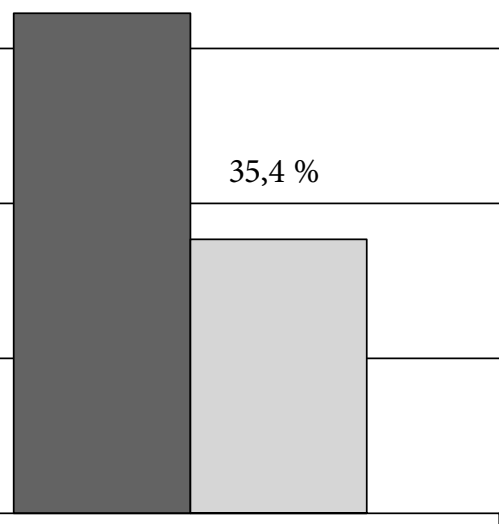

Siglo XXI

$\mathrm{X}^{\mathbf{2}}=2,205<\mathrm{X}^{2}{ }_{0.95,1}=3,84(\mathrm{p}=0,138>0,05)$

Gráfico 10 Distribución de ¿no? según época y sexo. 
¿Eh?

Este es el segundo marcador más empleado, aunque a bastante distancia de ¿no? También está muy extendido entre los hablantes: lo utilizaron un total de 56/96 sujetos, 58,3\% (23/48, 47,9 \% en las encuestas antiguas; $33 / 48,68,8 \%$ en las nuevas). Como se puede apreciar en el Gráfico 11, es un apéndice interrogativo que tiene mayor representatividad en las encuestas más recientes (100/630, 15,9\%).

$\square$ ¿eh? $\square$ otros

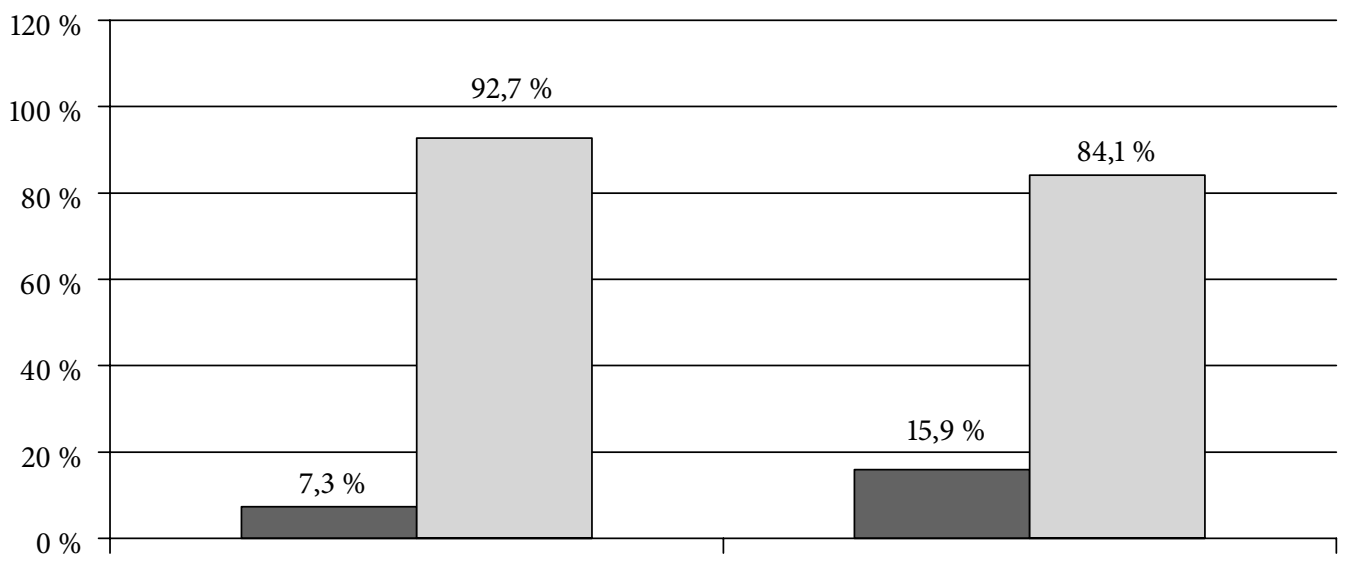

Siglo XX

Siglo XXI

$\mathbf{X}^{2}=27,519>\mathrm{X}^{2}{ }_{0.95,1}=3,84(\mathrm{p}=1,6>0,05)$

Gráfico 11 Representatividad de ¿eh? según época.

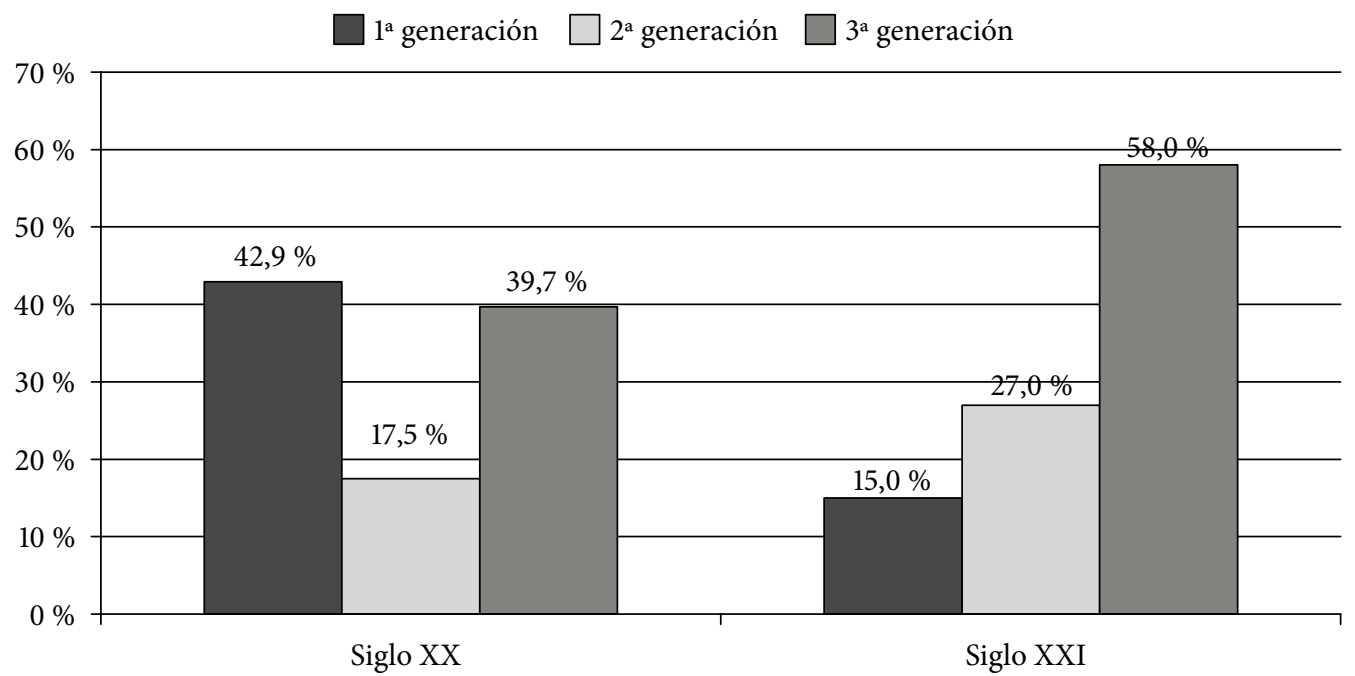

$\mathrm{X}^{2}=15,696>\mathrm{X}^{2}{ }_{0.95,2}=5,99(\mathrm{p}=0<0,05)$

Gráfico 12 Distribución de ¿ $e h$ ? según época y edad. 
Ahora bien, la mayoría de los casos de la submuestra del siglo XXI se concentran en la generación de edad más avanzada, frente a los jóvenes que revelan un acusado descenso (Gráfico 12). Si vemos que en los materiales del siglo XX los informantes de la primera generación constituían uno de los principales bloques promotores de este recurso, se puede decir que es una estrategia que ha pervivido con el paso del tiempo en ese grupo poblacional que en la actualidad está constituido por los informantes de más edad, pero la tendencia es que este apéndice interrogativo sea cada vez menos empleado en el habla de la ciudad. Eso se confirma, además, con el hecho de que se produce una progresión descendente de su empleo conforme disminuye la edad de los informantes en las grabaciones actuales.

\section{¿Sabes?}

Se trata de la tercera forma más empleada en las dos submuestras, con un claro incremento en el índice de usos en las encuestas más recientes (70/87, 80,5 \%). En ellas, además, este apéndice interrogativo tiene más representatividad con respecto a las otras formas empleadas (70/630, 11,1 \%) (Gráfico 13).

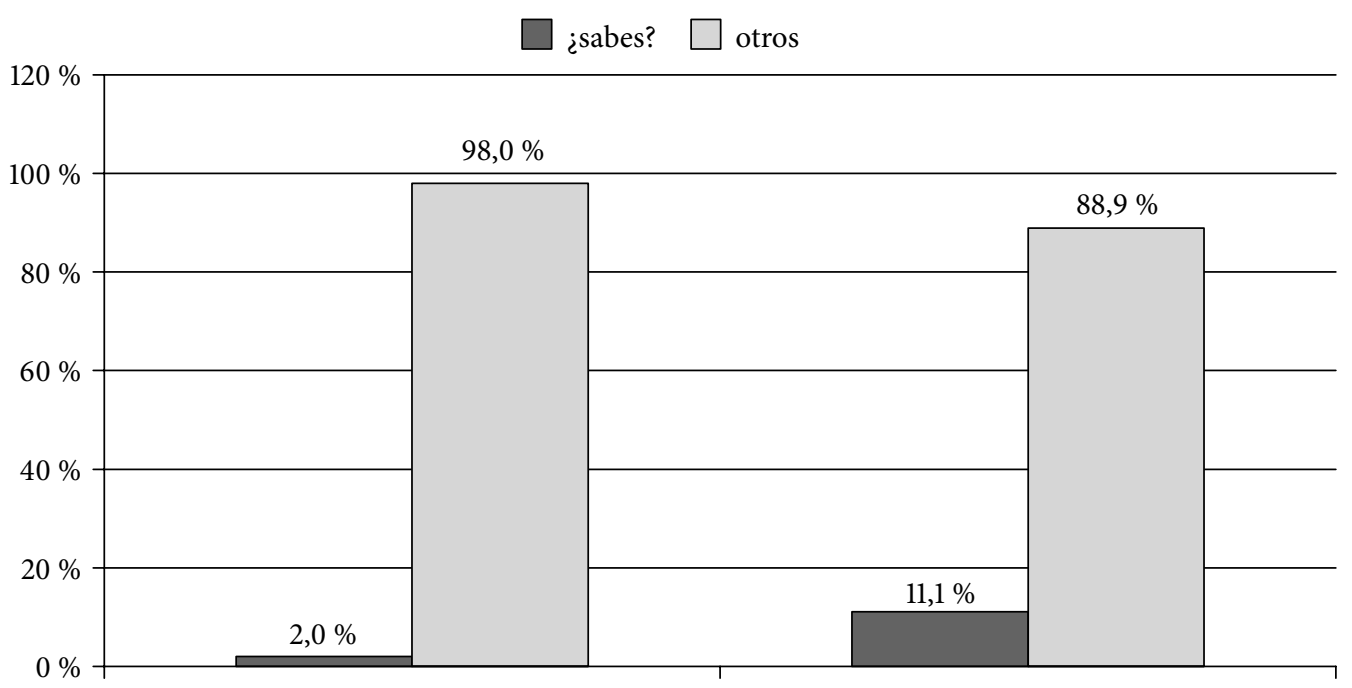

Siglo XX

Siglo XXI

$\mathbf{X}^{2}=55,542>\mathrm{X}^{2}{ }_{0.95,1}=3,84(\mathrm{p}=0<0,05)$

Gráfico 13 Representatividad de ¿sabes? según época.

La distribución por edad (Gráfico 14) nos muestra, además, que en los últimos años ¿sabes? es una partícula especialmente productiva entre los hablantes jóvenes, y también se percibe, por lo general, una progresión descendente conforme aumenta la edad de los sujetos. Se trata de un patrón diferente al de épocas precedentes, donde los principales promotores de esta forma eran los informantes de edad más avanzada y los jóvenes. Por tanto, no estamos ante una partícula de reciente inclusión, pero sí ante un uso que se ha ido afianzando como rasgo del habla juvenil en los últimos años. 


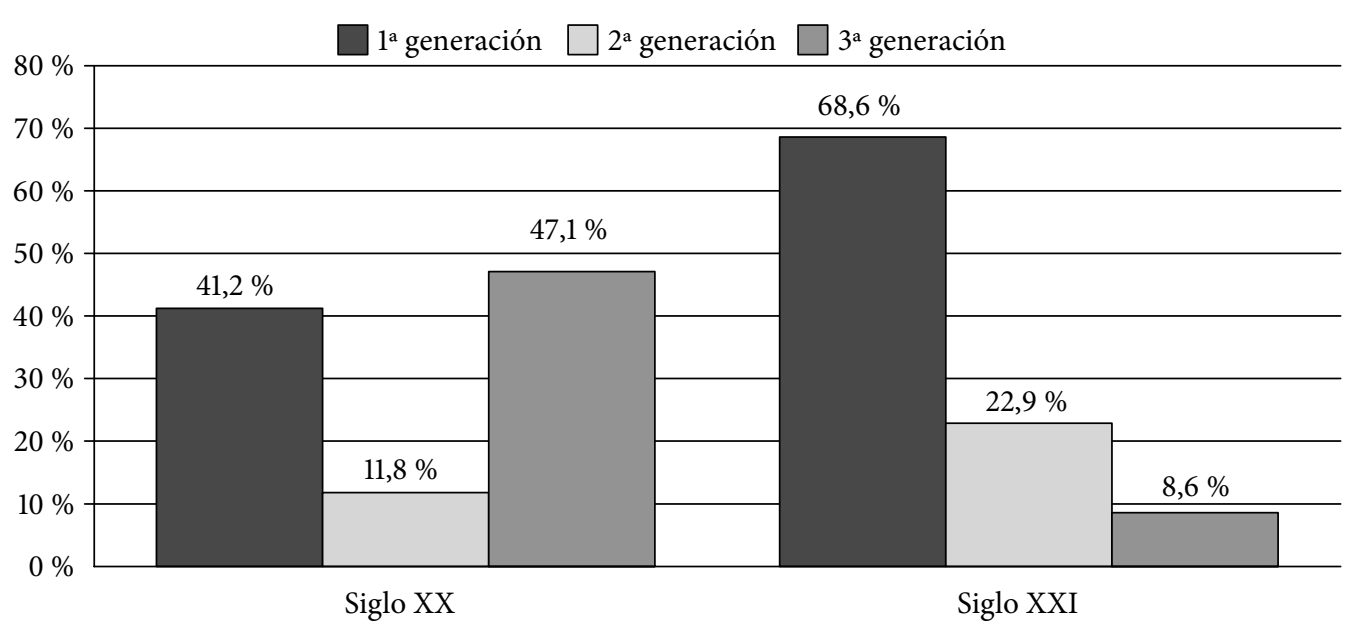

$\mathbf{X}^{2}=15,028>\mathrm{X}^{2}{ }_{0.95,2}=5,99(\mathrm{p}=0<0,05)$

Gráfico 14 Distribución de ¿sabes? según época y edad.

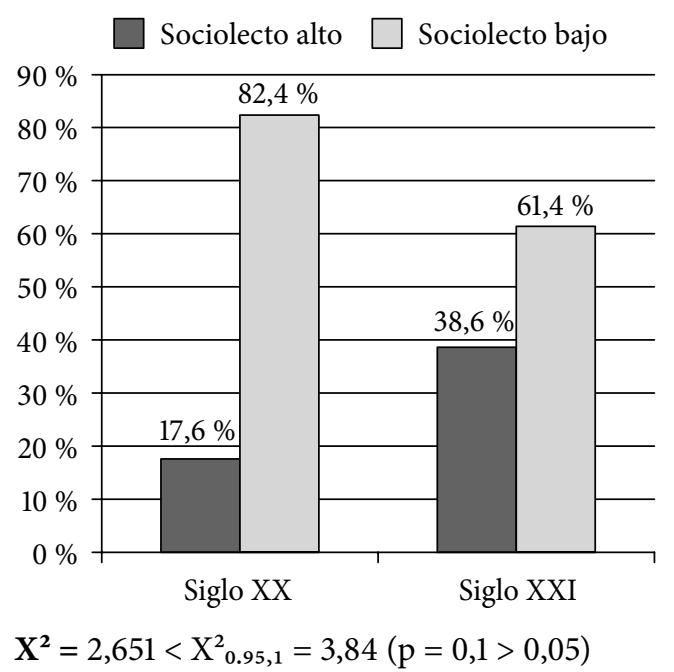

Gráfico 15 Distribución de ¿sabes? según época y sociolecto.

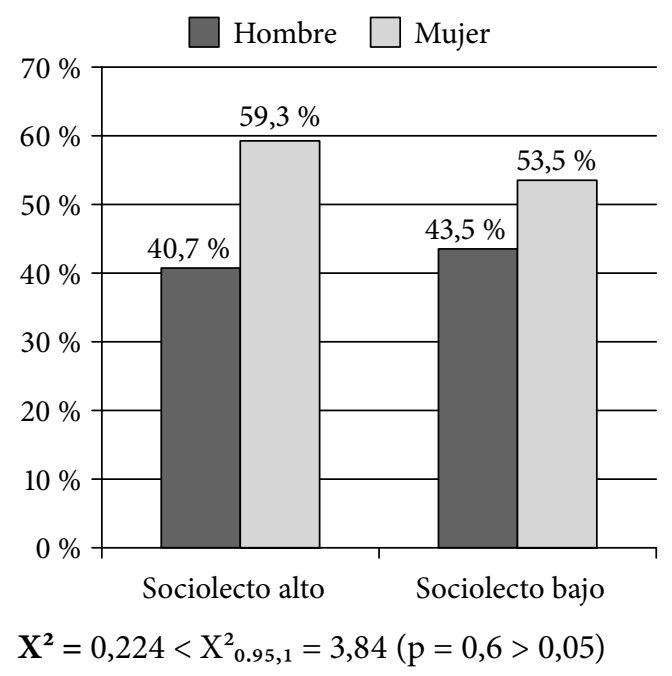

Gráfico 16 Distribución de ¿sabes? según época y sexo.

Los resultados de esta investigación corroboran los obtenidos en Santana (2019: 121): en la ciudad de Sevilla ¿sabes? es un apéndice más característico del sociolecto bajo ${ }^{4}$ (Gráfico 15), rasgo que se mantiene en las dos épocas analizadas aquí. El principal grupo impulsor de este uso en la actualidad es el de los jóvenes con escaso grado de instrucción (26/70, 37,1 \%). Molina (2006 y 2017) documentó el incremento de esta forma entre las mujeres cuando los sujetos tenían formación universitaria y entre los varones cuando

\footnotetext{
4 Este dato ayuda a explicar la escasa documentación que obtuvimos en el estudio de la norma culta (Santana 2017).
} 
tenían un grado de instrucción bajo. En las submuestras que hemos empleado para esta investigación el sexo no ha condicionado la distribución de esta partícula, pues las féminas lideraron su uso en ambos sociolectos y en las dos épocas (Gráfico 16).

\section{¿Verdad?}

Al contrastar las dos etapas cronológicas podemos observar que, si bien ¿verdad? no es un recurso muy extendido entre los sevillanos, por lo que hay que ser prudentes en las conclusiones que se obtengan, se aprecia que es una partícula que tiene menor grado de representatividad en la época actual (6/630, 1,0 \%) (Gráfico 17).

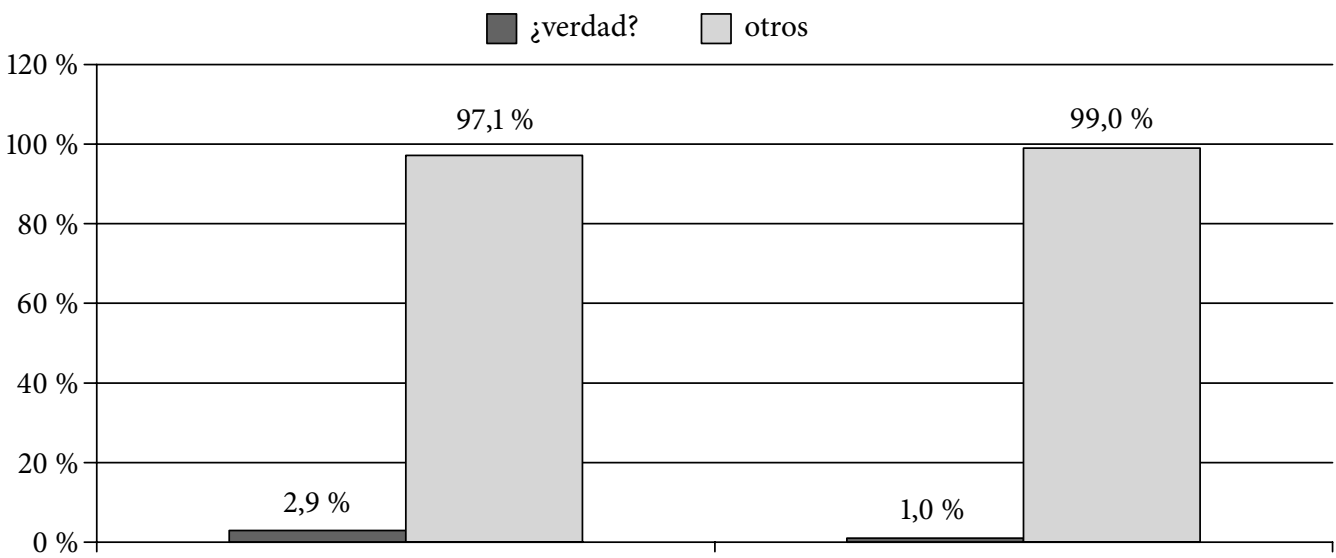

Siglo XX

Siglo XXI

$\mathrm{X}^{2}=6,772>\mathrm{X}_{0.95,1}^{2}=3,84(\mathrm{p}=0<0,05)$

Gráfico 17 Representatividad de ¿verdad? según época.

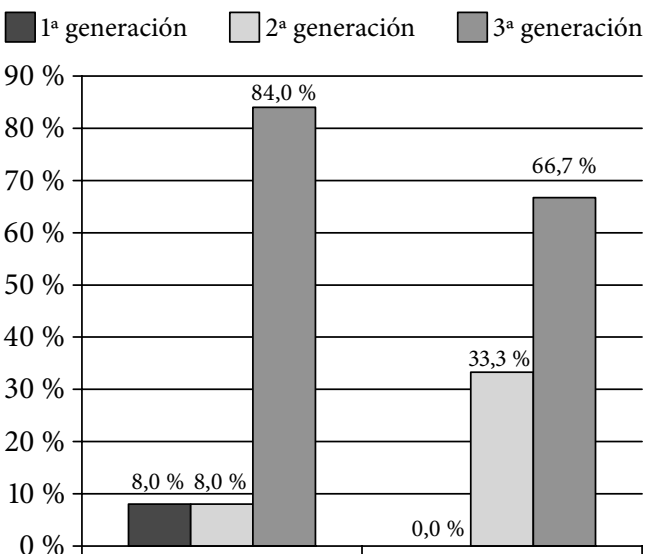

Siglo XX
Siglo XXI

$\mathrm{X}^{2}=3,067<\mathrm{X}^{2}{ }_{0.95,2}=5,99(\mathrm{p}=0,216>0,05)$

Gráfico 18 Distribución de ¿verdad? según época y edad.

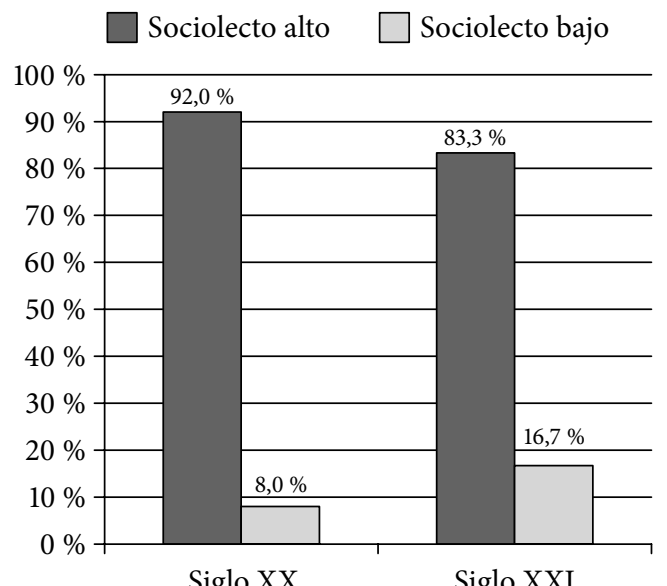

Siglo XX

$\mathrm{X}^{2}=0,416<\mathrm{X}^{2}{ }_{0.95,1}=3,84(\mathrm{p}=0,5>0,05)$

Gráfico 19 Distribución de ¿verdad? según época y sociolecto. 
En lo que respecta a la distribución sociolingüística, el factor edad arroja luz acerca del grado de envejecimiento de este apéndice (Gráfico 18). Es un recurso que ya era principalmente empleado por las generaciones de más edad a finales del siglo XX y que en la actualidad, a su acusado descenso hay que añadir la falta de registros en los informantes más jóvenes. Los datos, por tanto, apuntan hacia su progresiva desaparición del empleo habitual del habla de Sevilla. Además, es característica en los hablantes con nivel educativo alto (Gráfico 19), rasgo compartido por las dos épocas estudiadas.

\section{¿Comprendes? ¿Entiendes?}

¿Comprendes? es un apéndice que, a su ya escasa presencia entre los sevillanos encuestados (Gráfico 20), se suma una importante bajada en las encuestas recientes $(4 / 19,21,1 \%)$, con una representatividad menos significativa en ellas (4/630, 0,6 \%).

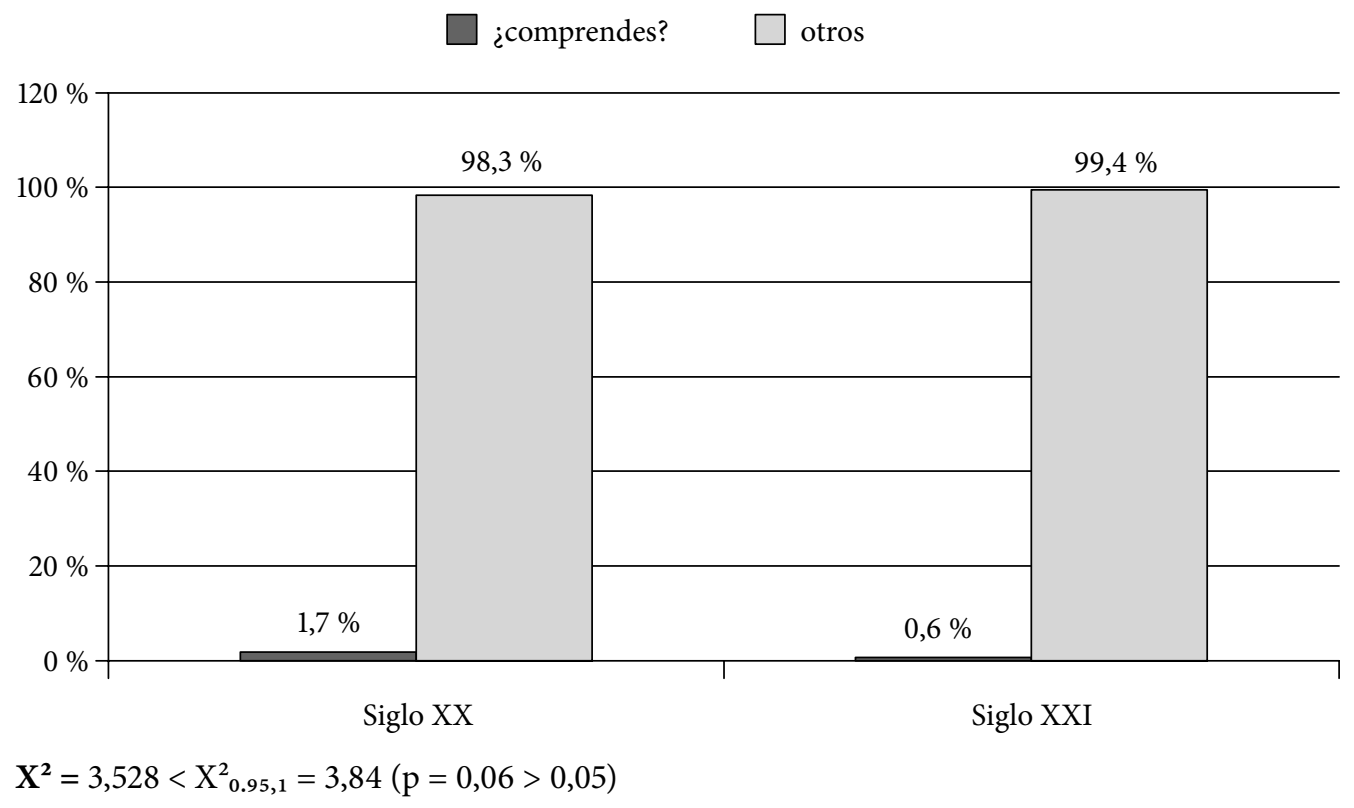

Gráfico 20 Representatividad de ¿comprendes? según época.

La relación con la edad (Gráfico 21) pone de manifiesto que, siempre con la prudencia que exige el bajo número de casos localizados, en las últimas décadas esta partícula ha quedado relegada a personas de la segunda y la tercera generación. Por tanto, se percibe la tendencia a su paulatino desuso en el habla de los sevillanos. La diferencia entre las dos submuestras es palpable cuando se aprecia que, frente al empleo más significativo en las primeras generaciones de finales del siglo XX, en las grabaciones recientes los jóvenes no registran ningún ejemplo. Se entiende que los casos documentados actualmente en las personas de más edad son hábitos que conservan de épocas precedentes. 
Teniendo en cuenta el carácter de sinonimia con ¿comprendes? observaremos también cuál fue el comportamiento de ¿entiendes? en los dos subcorpus. En esta ocasión la rentabilidad de la partícula mantiene una situación de equilibrio en ambas épocas (Gráfico 22), con una representatividad muy parecida.

$\square$ 1ª generación $\square$ 2a generación $\square$ 3ª generación

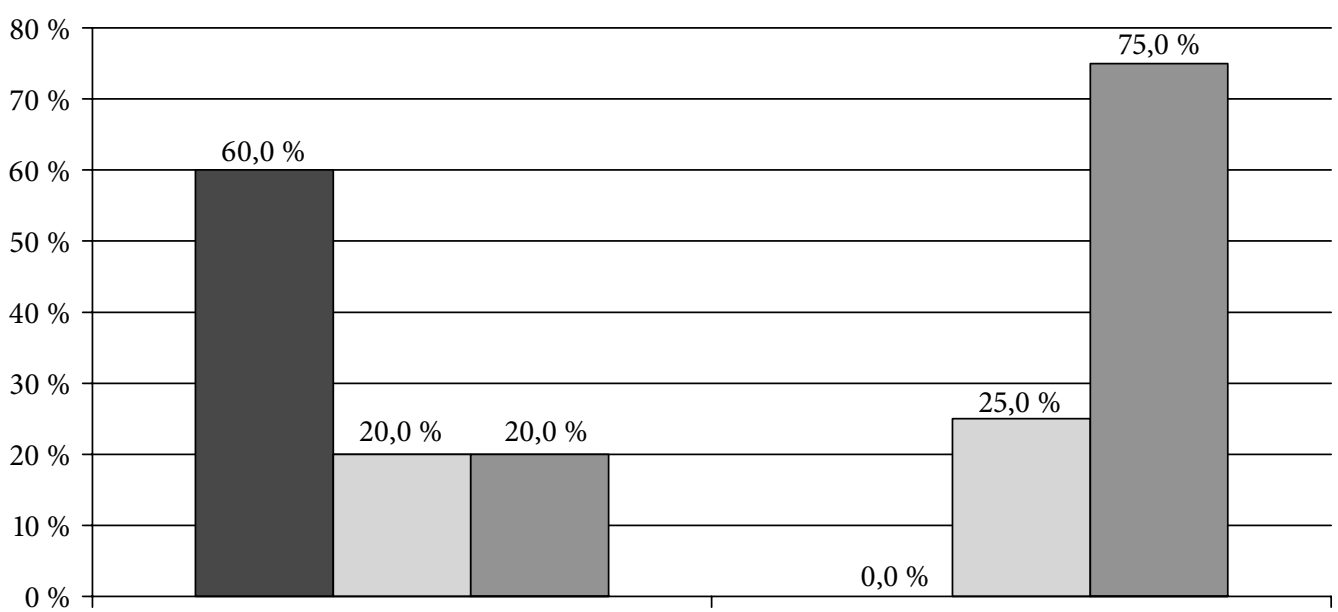

Siglo XX

Siglo XXI

$\mathrm{X}^{2}=5,463<\mathrm{X}_{0.95,2}^{2}=5,99(\mathrm{p}=0,065>0,05)$

Gráfico 21 Distribución de ¿comprendes? según época y edad.

$\square$ ¿entiendes? $\square$ otros

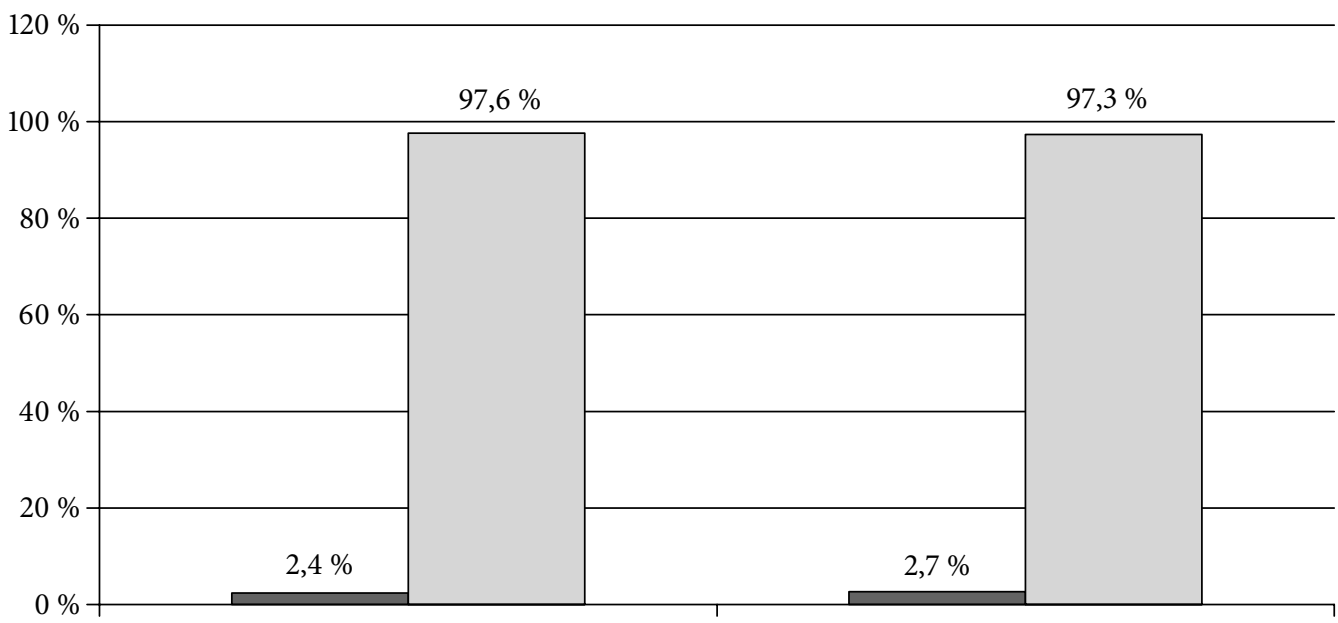

Siglo XX

Siglo XXI

$\mathrm{X}^{2}=0,103<\mathrm{X}^{2}{ }_{0.95,1}=3,84(\mathrm{p}=0,74>0,05)$

Gráfico 22 Representatividad de ¿entiendes? según época. 
Por su parte, la relación con la variable edad presenta bastantes similitudes con el comportamiento de ¿comprendes? (Gráfico 23). Una vez más, aun teniendo pocos ejemplos, se observa la tendencia a la desaparición de esta forma en el habla de Sevilla actual. Esto se deduce del hecho de que en las encuestas recientes no se documentó ningún caso entre los informantes más jóvenes. La proyección de uso es descendente conforme disminuye la edad de los encuestados.

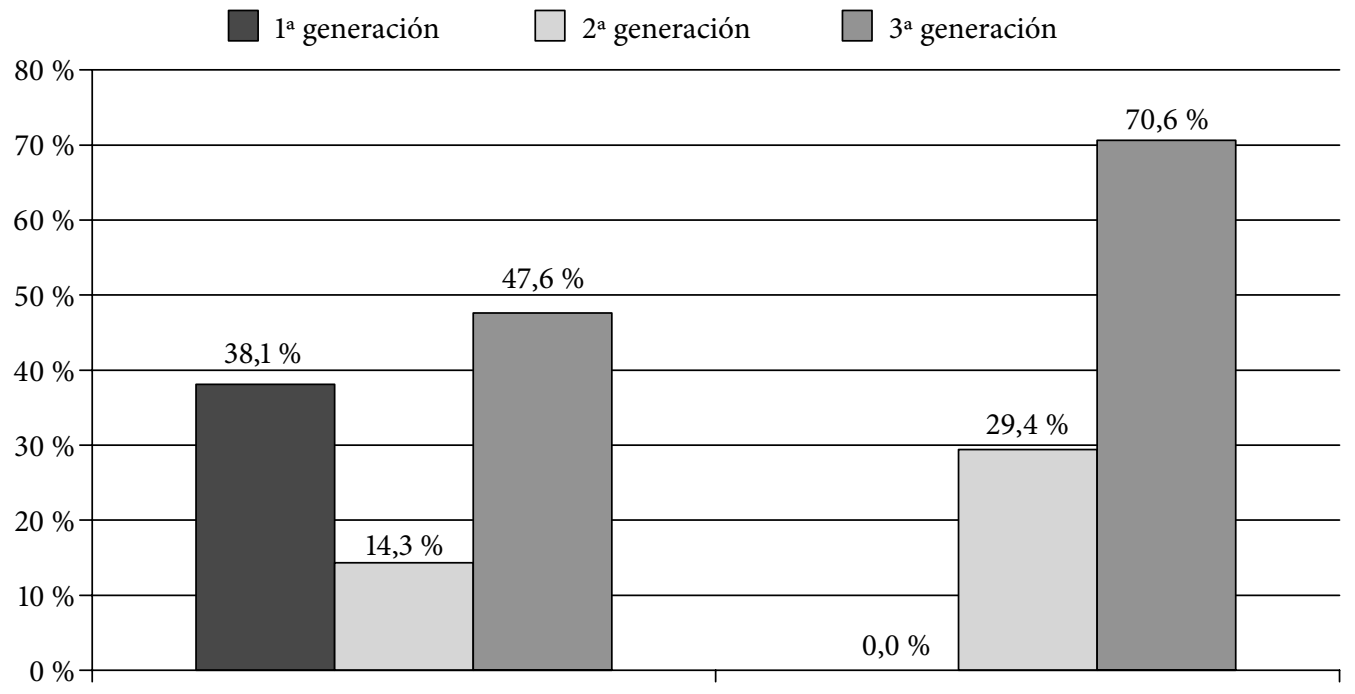

Siglo XX

Siglo XXI

$\mathrm{X}^{2}=8,353>\mathrm{X}_{0.95,2}^{2}=5,99(\mathrm{p}=0,01<0,05)$

Gráfico 23 Distribución de ¿entiendes? según época y edad.

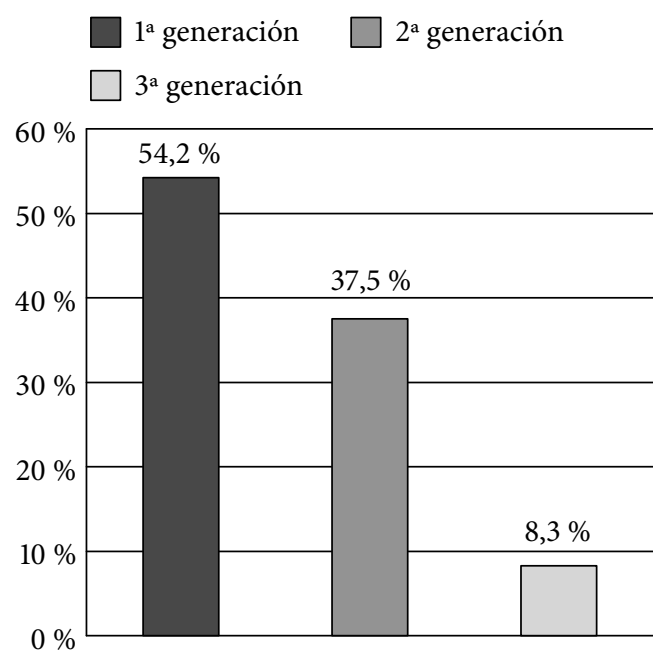

Gráfico 24 Distribución de ¿vale? según edad.

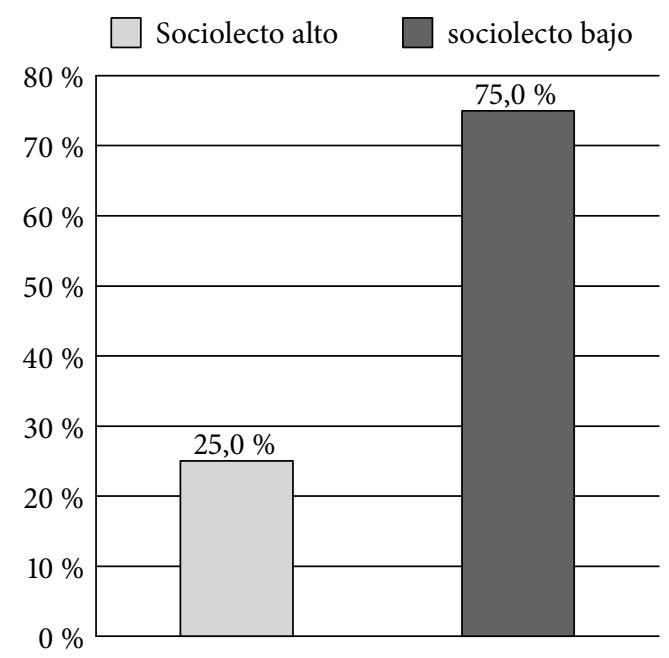

Gráfico 25 Distribución de ¿vale? según sociolecto. 


\section{¿Vale?}

La singularidad que aporta este apéndice interrogativo con respecto a las otras unidades analizadas es que solo se documentaron casos en la submuestra del siglo XXI. Además, se da la circunstancia de que su uso fue significativamente más característico de los sujetos de menor edad (Gráfico 24). De esta forma corroboramos los indicios iniciales (Santana 2019: 123): no solo es una partícula que actualmente es más empleada por los jóvenes sevillanos, sino que no se documentaron casos en las muestras de habla de los años setenta y ochenta. No queremos decir con ello que no fuera un recurso conocido o empleado en otra etapa, sino que su uso no era lo suficientemente representativo como para que apareciera un solo caso en los materiales analizados. Por tanto, podemos decir que es un apéndice interrogativo cuya propagación en el habla de la ciudad de Sevilla se está produciendo recientemente. Se advierte, además, que es una fórmula más extendida entre los encuestados con bajo grado de instrucción (Gráfico 25), principalmente las mujeres de la primera generación $(10 / 24,41,7 \%)$.

\section{CONCLUSIONES}

El estudio de los apéndices interrogativos en el habla de Sevilla contrastando dos épocas separadas por unos cuarenta años nos ha permitido observar que, de forma general, no hay grandes diferencias en cuanto al tipo de unidades empleadas y en lo que respecta al porcentaje de uso global en cada etapa cronológica. Son recursos ampliamente presentes en las dos submuestras, con un ligero incremento en los materiales de finales del siglo XX. Ahora bien, si nos detenemos en los marcadores específicos, hemos podido analizar la evolución de estas formas en el habla de la ciudad hispalense y corroborar la hipótesis de partida: hay unidades que están sufriendo cambios generacionales.

¿No? se consolida como la partícula característica entre los sevillanos en las dos épocas. Sin embargo, en las grabaciones más recientes se aprecia un importante descenso en su empleo entre los jóvenes, especialmente los del nivel educativo alto. Algo parecido sucede con ¿eh?, que se mantiene como la segunda forma más rentable en ambas submuestras, pero revela también una tendencia progresiva al desuso en informantes de menor edad de las grabaciones más recientes. Con índices de frecuencia significativamente más bajos, ¿verdad?, ¿comprendes? y ¿entiendes? revelan una acusada caída en la submuestra del siglo XXI. Se presentan registros principalmente en las terceras generaciones, hábitos que estos hablantes mantienen desde épocas precedentes, donde la distribución generacional era más equilibrada. A diferencia de los marcadores señalados arriba, ¿sabes? es un apéndice que ha cobrado más relevancia en los últimos años, principalmente entre los jóvenes. Y el cambio más significativo es el de ¿vale?, que, sin registros en la submuestra del siglo XX, se introduce como una moda entre los hablantes de menor edad, especialmente entre las mujeres con baja formación.

Con la perspectiva lineal que hemos adoptado en esta investigación corroboramos la hipótesis de partida: se han ido produciendo cambios generacionales en los hábitos 
lingüísticos de los sevillanos en lo que respecta al empleo de los apéndices interrogativos, pues en las grabaciones más recientes se aprecian tendencias que diferencian a los jóvenes de otros grupos etarios y también usos que particularizan el habla de los sujetos de más edad.

\section{BIBLIOGRAFÍA}

BRIZ, Antonio (2001) El español coloquial en la conversación: esbozo de pragmagramática. Barcelona, Ariel Lingüística.

Cestero, Ana María (2002) "La función fática del lenguaje en el discurso y en la conversación”. En: Miguel Casas Gómez, María Tadea Díaz Hormigo y María Dolores Muñoz Núñez (eds.) Actas del IV Congreso de Lingüística General. Vol. 2. Cádiz, Universidad de Cádiz: 617-629.

(2003) "El funcionamiento de los apéndices interrogativos en la conversación y en el discurso académico". En: Cristina Castillo y José Manuel Lucía (eds.) Decíamos ayer... Estudios de alumnos en honor a María Cruz García de Enterría. Alcalá de Henares, Universidad de Alcalá: 83-127.

---- (2019) "Apéndices interrogativos de control de contacto: estudio sociolingüístico". Cuadernos de Lingüística de El Colegio de México. 6 (1): 1-65. https://cuadernoslinguistica.colmex.mx/index.php/cl/article/view/111/pdf [10.05.2019].

Cestero, Ana María y Albelda, Marta (2012) "La atenuación lingüística como fenómeno variable". Oralia. 15: 77-124.

CoRTÉs, Luis (1998) "Marcadores del discurso y análisis cuantitativo". En: María Antonia Martín Zorraquino y Estrella Montolío (coords.) Los marcadores del discurso. Teoría y análisis. Madrid, Arco/Libros: 143-160.

Cortés, Luis y CAMACho, María Matilde (2005) Unidades de segmentación y marcadores del discurso. Madrid, Arco/Libros.

Fuentes, Catalina (1990a) "Apéndices con valor apelativo". En: Pedro Carbonero y María Teresa Palet (eds.) Habla de Sevilla y hablas americanas. Sociolingüística Andaluza. Vol. 5. Sevilla, Publicaciones de la Universidad de Sevilla: 171-196.

---- (1990b) "Algunos operadores de función fática". En: Pedro Carbonero y María Teresa Palet (eds.) Habla de Sevilla y hablas americanas. Sociolingüística Andaluza. Vol. 5. Sevilla, Publicaciones de la Universidad de Sevilla: 137-170.

(1990c) "Procedimientos intradiscursivos: decir y los explicativos". En: Pedro Carbonero y María Teresa Palet (eds.) Habla de Sevilla y hablas americanas. Sociolingüistica Andaluza. Vol. 5. Sevilla, Publicaciones de la Universidad de Sevilla: 103-123. (1993a) "Desde luego, por supuesto, naturalmente". En: Pedro Carbonero y Catalina Fuentes (eds.) Estudios sobre el enunciado oral. Sociolingüistica Andaluza. Vol. 8. Sevilla, Publicaciones de la Universidad de Sevilla: 127-159.

(1993b) “Conectores pragmáticos”. En: Esperanza Alcaide, María del Mar Ramos y Francisco Salguero (eds.) Estudios lingüísticos en torno a la palabra. Sevilla, Universidad de Sevilla: 71-104. 
Fuentes, Catalina y Brenes, Ester (2014) “Apéndices apelativos en el lenguaje parlamentario andaluz: variación pragmática”. Oralia. 17: 181-209.

GaluÉ, Dexy (2002) "Marcadores conversacionales: un análisis pragmático”. Boletín de Lingüística. 18: 27-48.

García Vizcaíno, María José (2005) "El uso de los apéndices modalizadores ¿no? y ¿ eh? en español peninsular”. En: Lotfi Sayahi y Maurice Westmoreland (eds.) Selected Proceedings of the Second Workshop on Spanish Sociolinguistics. Somerville (MA), Cascadilla Proceedings Project: 89-101.

Lamíquiz, Vidal (dir.) y Pineda, Miguel Ángel, ed. (1983) Encuestas del habla urbana de Sevilla. Nivel culto. Sociolingüística Andaluza. Vol. 2. Sevilla, Publicaciones de la Universidad de Sevilla.

LAmíquiz, Vidal (dir.) y Ropero, Miguel, ed. (1987): Encuestas del habla urbana de Sevilla. Nivel popular. Sociolingüística Andaluza. Vol. 4. Sevilla, Publicaciones de la Universidad de Sevilla.

Lewis Vergara, Eileen (2016) Análisis pragmático y sociolingüístico de los marcadores interrogativos de control de contacto en el habla de Santiago de Chile. Santiago-Chile, Universidad de Chile. http://www.repositorio.uchile.cl/bitstream/handle/2250/143618 [20.01.2019].

Martín Zorraquino, María Antonia y Portolés Lázaro, José (1999) “Los marcadores del discurso". En: Ignacio Bosque y Violeta Demonte (eds.) Gramática descriptiva de la lengua española. Vol. 3. Madrid, Espasa Calpe: 4051-4421.

MócCERo, Leticia (2010) "Las preguntas confirmatorias como indicadoras de posicionamiento intersubjetivo". Estudios Filológicos. 45: 67-78.

Molina, Isabel (2006) "La moda del ¿sabes? en el barrio de Salamanca de Madrid: un análisis sociolingüístico". En: Filología y lingüística. Estudios ofrecidos a Antonio Quilis. Vol. 1. Madrid: CSIC - UNED - Universidad de Valladolid: 1045-1056. (2017): "El apéndice interrogativo ¿sabes? y su doble difusión en la estructura social de la periferia de Madrid (Vallecas)". En: Lingüística en la Red XV. Monográfico. Procesos de variación y cambio en el español de España. Estudios sobre el corpus PRESEEA. http://www.linred.es/monograficos_pdf/LR-monografico15-articulo6. pdf [31.07.2018].

Ortega, Jenaro (1985) “Apéndices modalizadores en español: los comprobativos". En: Estudios románicos dedicados al profesor Andrés Soria Ortega. Vol. 1. Granada, Universidad de Granada: 239-255.

---- (1986) “Aproximación al mecanismo de la conversación”. Verba. 13: 269-290.

Pineda, Miguel Ángel y Ollero, Manuel (1992) Encuestas del habla urbana de Sevilla. Nivel medio. Sociolingüística Andaluza. Vol. 6. Sevilla, Publicaciones de la Universidad de Sevilla.

RodrígueZ MuÑoz, Francisco (2009) "Estudio sobre las funciones pragmadiscursivas de ¿no? y ¿eh? en el español hablado". Revista de Lingüística Teórica y Aplicada. 47 (1), I Sem.: 83-101.

SAN MARTín, Abelardo (2011) "Los marcadores interrogativos de control de contacto en el corpus PRESEEA de Santiago de Chile". Boletín de Filología de la Universidad de Chile. XLVI (2): 135-166. 
Santana, Juana (2014) "Marcadores del discurso de Sevilla". En: Alba Valencia (coord.) Cuadernos de la ALFAL. T. 5. Monográfico. Marcadores discursivos en la norma culta hispánica: 1964-2014: 277-311. https://www.mundoalfal.org/sites/default/files/ revista/05_cuaderno_010.pdf [29/07/2018].

(2015a) "Marcadores discursivos de Sevilla". En: Alba Valencia y Alejandra Vigueras (coords.) Más sobre marcadores hispánicos. Usos de España y América en el corpus de estudio de la norma culta. México D.F., UNAM: 443-490.

----- (2015b) "Marcadores del discurso y variación diastrática: estudio en el sociolecto bajo". En: Juana Santana (dir.), Marta León-Castro y Adamantía Zerva (eds.) La variación en el español actual. Estudios dedicados al profesor Pedro Carbonero. Sociolingüística Andaluza, Vol. 17. Sevilla, Editorial Universidad de Sevilla: 289-313. (2016) “Luego y después: uso discursivo y variación”. RILCE. Revista de Filología Hispánica. 32 (2): 513-535.

(2017) "Marcadores interrogativos de interacción conversacional en la norma culta hispánica". En: 90 años de la Academia Boliviana de la Lengua. La Paz, Academia Boliviana de la Lengua: 232-286.

---- (2019) "Los apéndices interrogativos en el corpus PRESEEA-Sevilla: sociolectos alto y bajo". Oralia. 22 (1): 111-127. 